\title{
The Macrophage Responses during Diabetic Oral Ulcer Healing by Liquid Coconut Shell Smoke: An Immunohistochemical Analysis
}

\author{
Meircurius Dwi Condro Surboyo ${ }^{10}$ Fatma Yasmin Mahdani ${ }^{1} \quad$ Diah Savitri Ernawati $^{1}$ \\ Andari Sarasati ${ }^{2}$ Fianza Rezkita² \\ ${ }^{1}$ Department of Oral Medicine, Faculty of Dental Medicine, \\ Universitas Airlangga, Surabaya, Indonesia \\ 2Department of Dental Science, Faculty of Dental Medicine, \\ Universitas Airlangga, Surabaya, Indonesia

\begin{abstract}
Address for correspondence Meircurius Dwi Condro Surboyo, DRG MKes, Department of Oral Medicine, Faculty of Dental Medicine, Universitas Airlangga, Surabaya 60132, Indonesia (e-mail: Meircurius-2015@fkg.unair.ac.id).
\end{abstract}

Eur J Dent:2020;14:410-414

\begin{abstract}
Keywords

- macrophages

- liquid smoke

- benzydamine hydrochloride

- oral ulcer

- coconut shell

Objectives Liquid coconut shell smoke (LC-SS) is used in natural food preservation for a long history. The purpose of this study was to analyze the role of LC-SS in macrophage responses during diabetic oral ulcer healing as medication.

Materials and Methods Oral ulcers were induced in the labial lower mucosa of the research subjects using a round steel blade following diabetic induction by means of alloxan. Twenty-four diabetic Wistar rats presenting oral ulcers were divided into two groups, a test group, which was given topical treatment of LC-SS and a control group, which was given benzydamine hydrochloride $(\mathrm{BHCl})$. The role of LC-SS in macrophages was assessed by means of immunohistochemistry for nuclear factor kappa B (NF-kB) and tumor necrosis factor- $\alpha$ (TNF- $\alpha$ ) expression.

Result LC-SS increased macrophages compared with $\mathrm{BHCl}(p=0.000)$. The LC-SS affected only TNF- $\alpha$ expression by stimulating NF-KB expression $(p=0.046)$ but did not macrophage numbers ( $p=0.861$ ).

Conclusion LC-SS has a stronger effect compared with $\mathrm{BHCl}$ on diabetic oral ulcer healing by increasing macrophage response to produce TNF- $\alpha$ while decreasing NF- $\kappa B$ expression.
\end{abstract}

\section{Introduction}

Liquid coconut shell smoke (LC-SS) is broadly used as a food preservative. ${ }^{1}$ Many studies reported that the potential for liquid smoke as a food preservative has a better value compared with synthetic preservatives. ${ }^{2}$ Liquid smoke is usually used as a natural preservative in poultry, fish, flesh, and processed flesh. Liquid smoke application is able to maintain the meat's protein, ${ }^{3}$ and fat content. ${ }^{4}$

The major problems associated with diabetic oral ulcers include delayed and persistent of inflammation. ${ }^{5}$ Wound healing basically consists of four stages: hemostasis, inflammation, proliferation, and remodeling. Under diabetic conditions, impaired wound healing occurs due to several stages of agitation. At the inflammation stage, cytokine proinflammatory and reactive oxygen species persistently increase causing elevated oxidative and inflammatory stress. ${ }^{6}$ During the proliferation stage, a process of re-epithelialization strongly correlated to angiogenesis occurs, which supports epithelia layer contraction in wounds. Diabetic conditions lead to inadequate vascular performance and poor vessel proliferation. Moreover, at the remodeling stage, impaired wound healing occurs because of delayed vascular vessel maturation. Thus, a diabetic condition causes impaired oral ulcer healing. In this case, the main treatment of oral ulcer is by the administering of topical drugs in the form of mouthwashes, dental gels, and pastes.?

The aspect of oral ulcers that most sufferers complain of is pain. Benzydamine hydrochloride $(\mathrm{BHCl})$ constitutes a topical 
nonsteroidal anti-inflammatory drug that is a topical form of oral ulcers treatment because of its anti-inflammatory properties. ${ }^{8}$ Commercially available $\mathrm{BHCl}$ has a $\mathrm{pH}$ of 4.5 to 5 causing it to dissolve rapidly in salivary $\mathrm{pH}^{9}{ }^{9}$ The mechanism of $\mathrm{BHCl}$ is related to its ability to reduce the presence of tumor necrosis factor- $\alpha$ (TNF- $\alpha$ ) without inhibition of cyclooxygenase. ${ }^{10}$ It's causing the disadvantages of $\mathrm{BHCl}$ as topical treatment for oral ulcer. ${ }^{9}$ The effectiveness of topical drugs, such as mouthwash, gel even paste, for oral ulcer therapy is determined by its ability to adhesion and its absorption in the lesion, ${ }^{11}$ and is able to provide analgesic effects rather than just anti-inflammatory drug. ${ }^{9}$

Several studies have demonstrated that LC-SS possesses analgesic properties ${ }^{12}$ in addition to the ability to stimulate fibroblast formation, ${ }^{13}$ increase collagen, ${ }^{14}$ and improve clinical oral ulcer healing. ${ }^{15}$ In empirical studies, LC-SS is able to reduce pain during burn wound healing and can be used as a natural preservative in meat. ${ }^{3}$ The main components of LC-SS are phenols and flavonoid that possess antioxidant, analgesic, anti-inflammatory, and antimicrobial properties that may play a role in accelerating ulcer healing process. Both components possess the redox properties of superoxide radical scavenger or contrary agents that protect cells from damage caused by the free radicals abundant under diabetic conditions. As a result, an increase in collagen levels, a reduction in vascular granulation tissue volume and lipid peroxidation activity, and activation of proline hydroxylase occur, which promote accelerated wound healing. ${ }^{13}$ While the several benefits of LC-SS in promoting wound healing are known, to date, no study indicating the potential anti-inflammatory properties of LS supporting diabetic oral ulcer healing has been conducted.

The purpose of this study was to assess the anti-inflammatory role of LC-SS in stimulating macrophages response in TNF- $\alpha$ expression through nuclear factor kappa B (NF- $\mathrm{kB}$ ) expression during in vivo studies of diabetic oral ulcers compared with $\mathrm{BHCl}$. The TNF- $\alpha$ and NF- $\mathrm{KB}$ expression is the crucial marker for inflammation and needs to be analyzed.

\section{Materials and Methods}

\section{Distilled Liquid Smoke Production}

Five kilos, cleaned and dried, of coconut shell obtained from fresh 5 to 6-month-old coconuts obtained from local markets in Surabaya had been used to produce liquid smoke. A pyrolysis process was conducted at $400^{\circ} \mathrm{C}$ prior to distillation at 120 to $150^{\circ} \mathrm{C}$ to produce distilled liquid smoke. ${ }^{15,16}$

\section{Subject Treatment and Experimental Design}

Ethical approval for this study was issued by the Health Experiment Committee; Faculty of Dental Medicine, Universitas Airlangga, Indonesia (No. 536/HRECC.FODM/ VIII/2019). The animal subjects of the study consisted of 24 two-month-old Wistar rats weighing 120 to $160 \mathrm{~g}$. The diabetic conditions of the subjects were approved as fasting glucose on the third day reached $>200 \mathrm{mg} / \mathrm{dL}$ after injection with a $150 \mathrm{mg} / \mathrm{kg}$ dose of alloxan monohydrate (Alloxan monohydrate; Sigma-Aldrich, St. Louis, Missouri, United States). After the subjects had been confirmed as diabetic, they were anesthetized with a combination of ketamine/xylazine, before a $10 \mathrm{~mm}$ oral ulcer in the lower labial mucosa was created using a round stainless blade (Surgical blade; No: 15, Ailee Company Limited, Busan, South Korea). ${ }^{15}$ After 24 hours, the clinical characteristics of the oral ulcer included a reddish edge with a yellowish-white base. Topical treatment with $\mathrm{BHCl}$ 0.12\% (Tantum Verde; Soho, Jakarta, Indonesia) and LC-SS was applied at a dose of $1 \mu \mathrm{L} / 1 \mathrm{gr}$ of body weight once a day for 5 days. ${ }^{14}$

\section{Histological and Immunohistochemical Analysis}

The histological analysis of macrophage numbers involved staining using hematoxylin-eosin. Immunohistochemical analysis was performed through Abcam monoclonal anti$\mathrm{NF}-\mathrm{kB}$ antibody for NF-kB expression and monoclonal antiTNF- $\alpha$ antibody for TNF- $\alpha$ expression by means of an indirect technique using Mayer's staining counterstains. The NF- $\mathrm{KB}$ and TNF- $\alpha$ expression in the macrophages was calculated. Blind analysis of all parameters by a single calibrated operator was performed under light microscopy at a magnification of $400 x$.

\section{Statistical Analysis}

The data collected was subjected to an independent $t$-test. Correlation models of macrophages, NF-KB, and TNF- $\alpha$ expression were analyzed using linear regression with Statistical Package for the Social Sciences (SPSS) 23.0 software for windows 8.1 (SPSS; Chicago, United States). The value considered significant was that of $p<0.05$.

\section{Results}

\section{Histological Analysis}

Histological analysis confirmed the oral ulcer present to constitute a loss of the epithelial layer of the labial fornix inci-

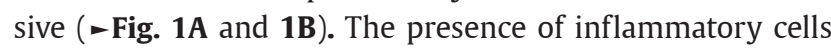
such as macrophages, neutrophils, and lymphocytes was also detected and confirmed as characteristic of an oral ulcer ( - Fig. 1C). LC-SS contained higher macrophages than $\mathrm{BHCl}$ $(p=0.000)(-$ Table $\mathbf{1})$.

\section{Immunohistochemical Analysis}

All groups presented positive immune-expression of NF- $\mathrm{KB}$ and TNF- $\alpha$ expression (-Fig. 1E and 1F). Topical treatment of LC-SS produced lower NF-KB expression than $\mathrm{BHCl}$ $(p=0.000)$, but the TNF- $\alpha$ expression is same as BHCL $(p=0.274)$ (-Fig. 2) (see - Table 1). The effect of LC-SS on TNF- $\alpha$ expression was $72.4 \%(R=0.724 ; p=0.036)$ that was stronger than BHCL at only $33.2 \%(R=0.332 ; p=0.594)$. The LC-SS affected the decrease in NF-кB expression $(a=0.765$; $p=0.046)$ but not the number of macrophages $(p=0.861)$. The $\mathrm{BHCl}$ produced no effect on NF-KB expression $(p=0.321)$ or macrophage numbers $(p=0.755)$ (see - Table 2 ). 

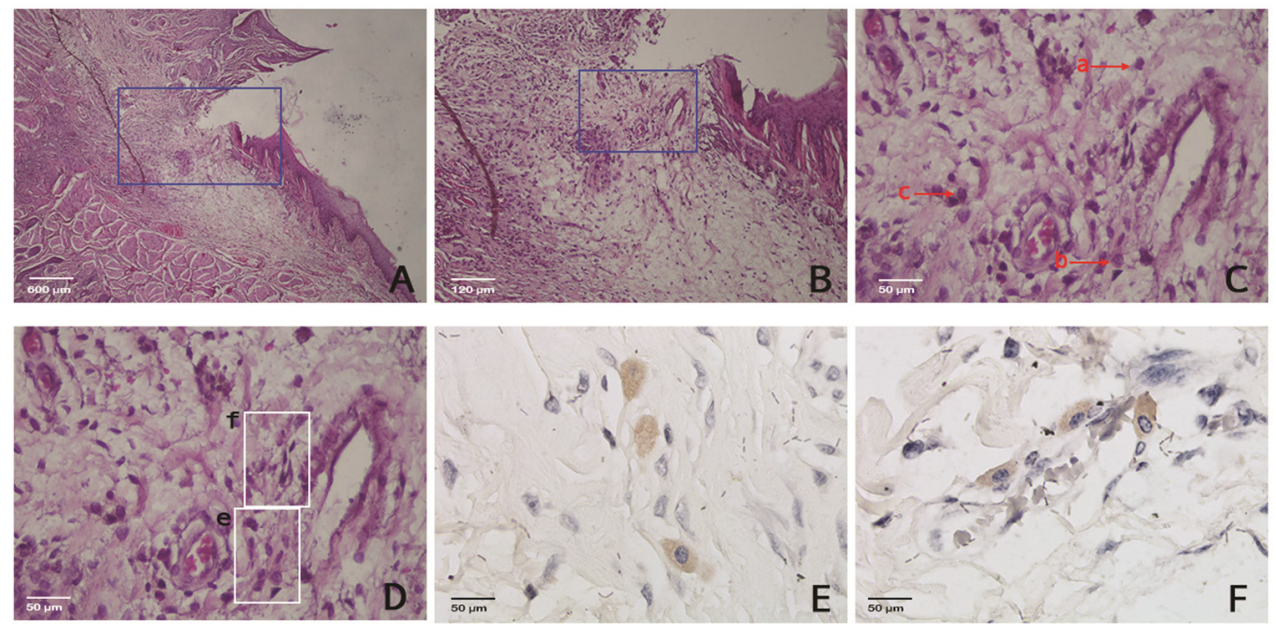

Fig. 1 Histology analysis of oral ulcer. (A) The loss of epithelial layers (magnification 40x). (B) Area of analysis (magnification 100x). (C) The inflammatory cell present, neutrophils (a), macrophages (b), and lymphocytes (c) (magnification 400x). (E) Nuclear factor kappa B expression on macrophages (magnification 400x). (F) tumor necrosis factor- $\alpha$ expression on macrophages (magnification 400x).

Table 1 Macrophages responses in the application of LC-SS and $\mathrm{BHCl}$

\begin{tabular}{|l|l|l|l|}
\hline \multirow{2}{*}{ Cellular responses } & \multicolumn{2}{|c|}{ Groups } & \multirow{2}{*}{$p$-Value } \\
\cline { 2 - 4 } & BHCl & LC-SS & \\
\hline Macrophages & $7.67 \pm 1.67$ & $12.83 \pm 3.01$ & 0.000 \\
\hline NF-KB expression & $101.50 \pm 29.65$ & $55.92 \pm 17.74$ & 0.000 \\
\hline TNF- $\alpha$ expression & $46.42 \pm 15.34$ & $40.75 \pm 8.43$ & 0.274 \\
\hline
\end{tabular}

Abbreviations: $\mathrm{BHCl}$, benzydamine hydrochloride; LC-SS, liquid coconut shell smoke; NF-kB, nuclear factor kappa B; $p$-value, significant difference at independent $t$-test $(p<0.05)$; TNF- $\alpha$, tumor necrosis factor- $\alpha$.

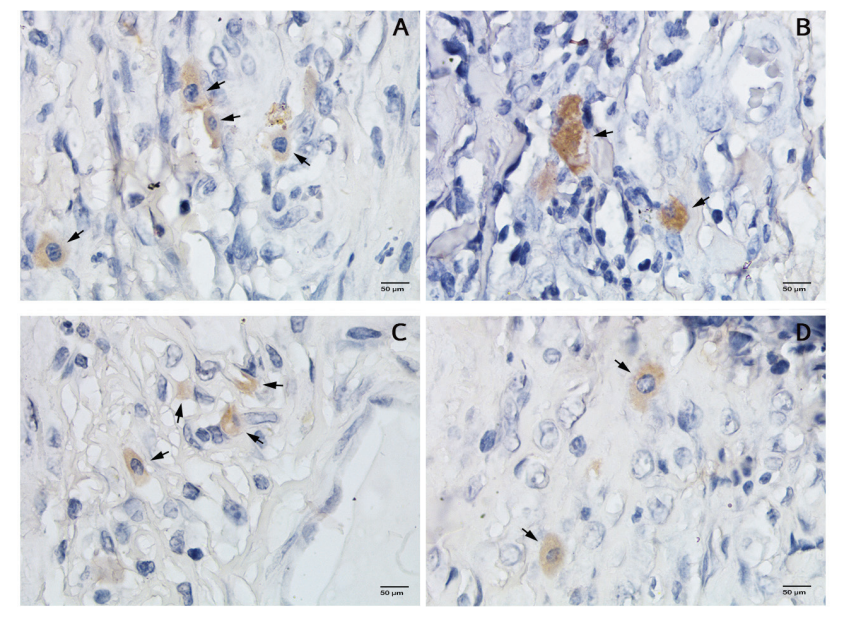

Fig. 2 Immunohistochemistry analysis. The nuclear factor kappa B expression on macrophages after topical treatment of benzydamine hydrochloride $(\mathrm{BHCl})(\mathbf{A})$ and liquid coconut shell smoke (LC-SS) (B) The tumor necrosis factor- $\alpha$ expression on macrophages after topical treatment of $\mathrm{BHCl}(\mathrm{C})$ and LC-SS (D) (magnification 400x).

\section{Discussion}

The process of oral ulcer healing involves the phases of hemostasis, inflammation, proliferation, and, finally, remodeling. Diabetes mellitus, constituting an impaired systemic condition, may affect the healing process during both the inflammatory and proliferation phases. ${ }^{17}$ Oral ulcers in diabetes mellitus are characterized by prolonged healing due to a more protracted inflammatory process due to an increase in TNF- $\alpha .^{18}$ The inflammatory process is a result of high glucose oxidation increasing the production of superoxide $\left(\mathrm{O}^{2}\right)$ free radicals by mitochondria that are then converted into hydroxyl $(-\mathrm{OH})$ and peroxide $\left(\mathrm{H}_{2} \mathrm{O}_{2}\right)$.

LC-SS is the result of coconut shell decomposition. Lignin, as the main component of coconut shell, will decompose into phenolic compound during pyrolysis. The main phenolic compounds in LC-SS are phenol, guaiacol, and 4-ethly-2methoxyphenol. ${ }^{16}$ Phenolic compound has a hydroxyl group $(-\mathrm{OH})$ that is directly bound to an aromatic hydrocarbon ring. ${ }^{19}$ Previous research has shown that topical treatment of LC-SS promotes oral ulcer healing ${ }^{15}$ by increasing the production of collagens. ${ }^{14}$ Phenolic compounds in LC-SS demonstrate the ability to decrease TNF- $\alpha$ expression in diabetic oral ulcers by increasing macrophages responses and decreasing NF- $\mathrm{KB}$ expression. The hydroxyl group $(-\mathrm{OH})$ is able to bind superoxide $\left(\mathrm{O}_{2}^{-}\right)$during signaling to produce proinflammatory cytokines such as TNF- $\alpha$. The binding of superoxide $\left(\mathrm{O}_{2}^{-}\right)$inhibits phosphorylation and IkB kinase (IKK) activation, the degradation of inhibitor of nuclear factor kappa B (IkB), translocation of NF-kB, and the phosphorylation of p65 in the cell nucleus. Therefore, the activation and expression of NF- $\mathrm{kB}$ decrease, in turn, inducing a reduction in TNF- $\alpha$ expression. ${ }^{20}$

This study, however, showed that LC-SS produces no significant effect on macrophages, but does so with regard to NF- $\mathrm{KB}$ expression. The number of macrophages in the LC-SS was higher 
Table 2 The effect of LC-SS and BHCl to TNF- $\alpha$ expression through macrophages and NF-KB expression

\begin{tabular}{|c|c|c|c|c|c|c|}
\hline Treatment & Variable & $p$-Value & $R$ & $\alpha$ & $a$ & sig \\
\hline \multirow[t]{2}{*}{$\mathrm{BHCl}$} & Macrophages & \multirow[t]{2}{*}{0.594} & \multirow[t]{2}{*}{0.332} & 3.183 & 0.347 & 0.321 \\
\hline & $N F-\kappa B$ & & & 0.055 & 0.106 & 0.755 \\
\hline \multirow[t]{2}{*}{ LC-SS } & Macrophages & \multirow[t]{2}{*}{0.036} & \multirow[t]{2}{*}{0.724} & -0.166 & -0.059 & 0.861 \\
\hline & $N F-\kappa B$ & & & 0.364 & 0.765 & 0.046 \\
\hline
\end{tabular}

Abbreviations: ANOVA, analysis of variance; BHCl, benzydamine hydrochloride; LC-SS, liquid coconut shell smoke; NF- $\mathrm{kB}$, nuclear factor kappa B; TNF- $\alpha$, tumor necrosis factor- $\alpha$.

Note: a, coefficients of regression; $p$-value, value of ANOVA significance; $R$, coefficients of correlation; sig, value of significance $(p<0.05) ; \alpha$, constantan.

than in the $\mathrm{BHCl}(p=0.000)$. Analysis of data produced during this study found that LC-SS has no inhibition effect on macrophage activity $(p=0.861)$. Consequently, higher macrophage counts in LC-SS may be caused by monocyte migration response through chemokines such as monocyte chemoattractant protein- 1 due to inflammation and oxidative stress resulting from a diabetic condition. ${ }^{21}$ Studies report that phenol contained in LC-SS causes inhibition of IKK activation culminating in a reduction in NF- $\kappa B$ activity. However, the research conducted by the authors found that LC-SS has a significant inhibition effect on NF- $\mathrm{KB}$ $(p=0.046)$, although NF- $\mathrm{kB}$ expression in LC-SS is significantly lower than that in $\mathrm{BHCl}(p=0.000){ }^{22}$ This indicates that LC-SS affects NF- $\mathrm{kB}$ expression and activity in cells other than macrophages such as monocytes, dendritic cells, mast cells, and $\mathrm{T}$ lymphocytes. ${ }^{23}$ Besides affecting macrophages, phenolic compounds in LC-SS utilize several potential pathways to inhibit NF- $\mathrm{KB}$ by THP-1-activated human monocytes, the degradation

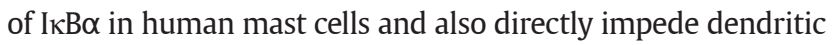
cells. Such inhibition leads to a decrease in TNF- $\alpha$ expression. ${ }^{24}$

Various studies showed that phenol in LC-SS affects NF- $\kappa B$ expression in macrophages through inhibition of the I $\mathrm{K} B$ kinase (IKK) complex that consists of regulatory (IKK $\gamma$ ) and catalytic (IKK $\alpha$ and IKK $\beta$ ) pathways in the canonical pathway. This pathway promotes the rapid and transient activation of NF- $\mathrm{KB}$. Therefore, the role of LC-SS in NF- $\mathrm{kB}$ activity in macrophages is estimated through stimulation of noncanonical pathways with the activation of NF- $\mathrm{KB}$-inducing kinase (NIK). This pathway has role to activate NF- $\mathrm{KB}$ more slowly and with longer-lasting results than canonical signaling. ${ }^{25}$ This is proven by various studies that suggest that NIK is induced and overactivated in obese patients and contributes to hyperglycemia, insulin resistance, and glucose intolerance through its effect on pancreatic $\beta$-cells. ${ }^{26}$ Phenol in LC-SS has a role in binding NF- $\mathrm{kB}$ to DNA that can cause anti-inflammatory effects, which reduce chronic inflammatory conditions in diabetic patients. Moreover, phenols possess antioxidant properties capable of adjusting the oxidant levels in cells, thereby inflecting NF- $\mathrm{\kappa B}$ activation pathways. ${ }^{24}$

Insulin resistance commonly occurs in diabetic patients and is known to be closely related to overactivated and overdifferentiated T-cells, together with the inflammatory pathway activation. NF- $\mathrm{KB}$ activation in T-cells can be caused by chronic inflammation and insulin resistance that results in an increase in proinflammatory cytokine release. Increased proinflammatory pathway will increase the expression of cytokines and chemokines during the recruitment process in immune cells. This process resulting the initiation of $\mathrm{CD}^{+}$cell infiltration and an increase in human leukocyte antigen-DR expression (HLA-DR) on the surface of antigen-presenting cells that plays a crucial role in lymphocyte activation. ${ }^{27} \mathrm{HLA}-\mathrm{DR}$ then interacts with the $\mathrm{T}$ cell receptor to activate NF- $\mathrm{kB}$ expression in T-cells via the linker and protein adapter pathways. T cell infiltration due to increased immune response can also cause greater mast cell activity. Mast cells are known to degranulate when coming into direct contact with T cells, subsequently releasing TNF- $\alpha .^{28}$

Healing in diabetic wounds can be promoted by neutralizing TNF- $\alpha$ secretion. Increased secretion of TNF- $\alpha$ can enhance endothelial cells apoptosis and fibroblasts that influence the process of angiogenesis. Inhibition of TNF- $\alpha$ secretion during hyperglycemia can increase the proliferation and migration of these cells. ${ }^{17}$ Fibroblasts also play a role in the synthesis of extracellular matrix proteoglycans in the reformation and repair of normal tissue structures. ${ }^{29}$

In addition to anti-inflammatory properties, the polyphenols in LC-SS demonstrate the ability to diminish insulin resistance by activating AMP-activated protein kinase leading to increased glucose uptake, inhibition of phosphatidylinositol 3-kinase /AkT and c-Jun $\mathrm{N}$-terminal kinase, and apoptosis pancreatic $\beta$-cell reduction that can enhance secretion of insulin. ${ }^{24}$ These LC-SS capabilities may hasten oral ulcer healing in diabetics.

\section{Conclusion}

As indicated by in vivo studies, LC-SS has a stronger effect compared with $\mathrm{BHCl}$ in diabetic oral ulcer healing by increasing macrophages responses through reduced NF- $\mathrm{BB}$ expression and TNF- $\alpha$ expression.

\section{Funding}

This study was funded by the Faculty of Dental Medicine Universitas Airlangga, Surabaya, Indonesia 2019, under grant 1408/UN3/2019.

\section{Conflict of Interest}

None declared.

\section{References}

1 Rozum J, Liquid Smoke (Smoke Condensate) Application. In: Encyclopedia of Meat Sciences. Elsevier Ltd; London, UK; 2014:315-320 
2 Achmadi SS, Mubarik NR, Nursyamsi R, Septiaji P. Characterization of redistilled liquid smoke of oil-palm shells and its application as fish preservatives. J Appl Sci (Faisalabad) 2013;13(3):401-408

3 Yusnaini S, Suryanto E, Armunanto R. Physical, chemical and sensory properties of Kenari (Canariun indicum L.) shell liquid smoke-immersed-beef on different level of dilution. J Indones Trop Anim Agric 2012;37(1):27-33

4 Swastawati F, Susanto E, Cahyono B, Trilaksono WA. Sensory evaluation and chemical characteristics of smoked stingray (Dasyatis Blekeery) processed by using two different liquid smoke. Int J Biosci Biochem Bioinform 2012;2(3):212-216

5 Tripathi R, Tripathi K. Management of non healing oral ulcer in diabetic patient using topical application of epidermal growth factor: a case report. Sch Acad J Biosci 2015;3(8):640-643

6 Salazar JJ, Ennis WJ, Koh TJ. Diabetes medications: impact on inflammation and wound healing. J Diabetes Complications 2016;30(4):746-752

7 Belenguer-Guallar I, Jiménez-Soriano Y, Claramunt-Lozano A. Treatment of recurrent aphthous stomatitis. A literature review. J Clin Exp Dent 2014;6(2):e168-e174

8 Pandya M, Kalappanavar AN, Annigeri RG, Rao DS. Relative efficacy of quercetin compared with benzydamine hydrochloride in minor aphthae: a prospective, parallel, double blind, active control, preliminary study. Int J Dent 2017;2017:7034390

9 Karavana Hizarcioğlu SY, Sezer B, Güneri P, et al. Efficacy of topical benzydamine hydrochloride gel on oral mucosal ulcers: an in vivo animal study. Int J Oral Maxillofac Surg 2011;40(9):973-978

10 Hanani T, Gadban H, Jahshan F, Ronen O. Tantum verde mouthwash for tonsillectomy: a prospective, double-blind, randomized control trial. Int J Pediatr Otorhinolaryngol 2019;121(January) :173-178

11 Aslani A, Zolfaghari B, Davoodvandi F. Design, formulation and evaluation of an oral gel from Punica Granatum Flower extract for the treatment of recurrent aphthous stomatitis. Adv Pharm Bull 2016;6(3):391-398 [Internet]

12 Surboyo MDC, Tantiana T, Arundina I. Analgesic effect of coconut shell (Cocos nucifera L) liquid smoke on mice. Dent J 2012;45(3):156-160 (Majalah Kedokt Gigi)

13 Tarawan VM, Mantilidewi KI, Dhini IM, Radhiyanti PT, Sutedja E. Coconut shell liquid smoke promotes burn wound healing. J Evid Based Complementary Altern Med 2017;22(3):436-440

14 Surboyo MDC, Arundina I, Rahayu RP. Increase of collagen in diabetes-related traumatic ulcers after the application of liquid smoke coconut shell. Dent J 2017;71(32):71-75 (Majalah Kedokt Gigi)

15 Surboyo MDC, Ernawati DS, Arundina I, Rahayu RP. Oral ulcer healing after treatment with distilled liquid smoke of coconut shell on diabetic rats. J Krishna Inst Med Sci Univ 2019;8(2):70-79
16 Surboyo MDC, Arundina I, Rahayu RP, Mansur D, Bramantoro T. Potential of distilled liquid smoke derived from coconut (Cocos nucifera L) shell for traumatic ulcer healing in diabetic rats. Eur J Dent 2019;13(2):271-279

17 Xu F, Zhang C. T graves D. abnormal cell responses and role of TNF alpha in impaired diabetic wound healing. Hindawi. Biomed Res Int 2013;2013:754802

18 Oliveira BV, Barros Silva PG, Nojosa JdeS, et al. TNF-alpha expression, evaluation of collagen, and TUNEL of Matricaria recutita L. extract and triamcinolone on oral ulcer in diabetic rats. J Appl Oral Sci 2016;24(3):278-290

19 Gülç̣in I, Beydemir S. Phenolic compounds as antioxidants: carbonic anhydrase isoenzymes inhibitors. Mini Rev Med Chem 2013;13(3):408-430

20 Costa G, Francisco V, Lopes MC, Cruz MT, Batista MT. Intracellular signaling pathways modulated by phenolic compounds: application for new anti-inflammatory drugs discovery. Curr Med Chem 2012;19(18):2876-2900

21 Tan H, Wang N, Li S, Hong M, Wang X, Feng Y. The reactive oxygen species in macrophage polarization: human diseases. Oxid Med Cell Longev 2016;2016:1-16

22 Basli A, Belkacem N, Amrani I, Health Benefits of Phenolic Compounds Against Cancers. In: Sato-Hernandez M, Palma-Tenago M, Garcia-Mateos $M$ del $R$, editors. Phenolic Compounds - Biological Activity [Internet]. InTech; 2017. Available at: http://www.intechopen. com/books/phenolic-compounds-biological-activity/ health-benefits-of-phenolic-compounds-against-cancers

23 Basli A, Belkacem N, Amrani I. et al. STAT3 and NF-кB are simultaneously suppressed in dendritic cells in lung cancer. Sci Rep 2017;7(February) :1-11

24 Yahfoufi N, Alsadi N, Jambi M, Matar C. The immunomodulatory and anti-inflammatory role of polyphenols. Nutrients 2018;10(11):1-23

25 Sun SC. The non-canonical NF-kB pathway in immunity and inflammation. Nat Rev Immunol 2017;17(9):545-558

26 Meyerovich K, Ortis F, Cardozo AK. The non-canonical NF-кB pathway and its contribution to $\beta$-cell failure in diabetes. J Mol Endocrinol 2018;61(2):F1-F6

27 Cajander S, Rasmussen G, Tina E, et al. Dynamics of monocytic HLA-DR expression differs between bacterial etiologies during the course of bloodstream infection. PLoS One 2018;13(2):e0192883

28 Thaker YR, Schneider H, Rudd CE. TCR and CD28 activate the transcription factor NF-B in T-cells via distinct adaptor signaling complexes. Immunol Lett 2015;163(1):113-119

29 Mescher AL. Macrophages and fibroblasts during inflammation and tissue repair in models of organ regeneration. Regeneration (Oxf) 2017;4(2):39-53 